\title{
Treatment variability and outcome differences in the emergency department management of alcohol withdrawal
}

\author{
Meldon Kahan, MD; ${ }^{*}$ Bjug Borgundvaag, MD, PhD ${ }^{\dagger}$ Deana Midmer, BSc, RN, EdD; ${ }^{\ddagger}$ \\ Diane Borsoi, MSc;§ Carol Edwards, RN;§ Noor Ladhani, BSc, MD ${ }^{\mathbb{I}}$
}

\begin{abstract}
Objective: Evidence suggests that symptom-triggered benzodiazepine treatment for patients with alcohol withdrawal reduces complication rates and emergency department lengths of stay. Our objective was to describe the management of alcohol withdrawal in 2 urban emergency departments.

Methods: A structured chart audit was performed for patients with alcohol-related problems who presented to 2 Toronto hospitals over a 2-year period.

Results: A total of 209 emergency department charts were audited. Patient characteristics were similar in both hospitals. None of the patients had been assessed using the Clinical Institute Withdrawal Assessment for Alcohol (CIWA-Ar) scale. Patients at one hospital received substantially higher mean diazepam doses $(64 \mathrm{mg}$ v. $26 \mathrm{mg} ; p<0.001)$ than did the patients at the other hospital, and the patients at the first hospital had fewer seizures during their emergency department stay $(1 \%$ v. $9 \% ; p=0.012)$. Patients spent an average of 9 hours and 40 minutes in the emergency department.

Conclusion: There is significant variability in the documentation and treatment of alcohol withdrawal. Lower benzodiazepine doses are associated with higher rate of withdrawal seizures and prolonged emergency department length of stay. A standardized approach using symptomtriggered management is likely to improve outcomes for patients presenting with alcohol withdrawal.
\end{abstract}

Key words: alcohol withdrawal; alcohol dependence; benzodiazepines

RÉSUMÉ

Objectif : Les données probantes indiquent qu'un traitement aux benzodiazépines déclenché par des symptômes chez les patients en sevrage de l'alcool réduit les taux de complication et la durée du séjour à l'urgence. Nous voulions décrire la prise en charge du sevrage de l'alcool dans deux services d'urgence urbains.

Méthodes: Nous avons procédé à une vérification structurée des dossiers de patients qui se sont

\footnotetext{
*St. Joseph's Health Centre, Toronto, Ont.

tMount Sinai Hospital, Toronto, Ont.

¥Department of Family and Community Medicine, University of Toronto, Toronto, Ont.

$\S$ Centre for Addiction and Mental Health, Toronto, Ont.

ףUniversity of Western Ontario, London, Ont.
}

Received: Feb. 14, 2004; final submission: Oct. 2, 2004; accepted: Oct. 21, 2004

This article has been peer reviewed.

Can J Emerg Med 2005;7(2):87-92 
présentés à deux hôpitaux de Toronto avec des problèmes d'alcool sur une période de deux ans. Résultats : Nous avons vérifié au total 209 dossiers de services d'urgence. Les caractéristiques des patients se ressemblaient dans les deux hôpitaux. Aucun des patients n'avait été évalué au moyen de l'échelle d'évaluation du sevrage de l'alcool de l'Institut clinique (CIWA-Ar). À un hôpital, les patients ont reçu des doses moyennes beaucoup plus fortes de diazépam (64 mg c. 26 mg; $p<$ $0,001)$ qu'à l'autre hôpital, et les patients du premier ont eu moins de crises épileptiques au cours de leur séjour à l'urgence ( $1 \%$ c. $9 \% ; p=0,012)$. Les patients ont passé en moyenne 9 heures et 40 minutes à l'urgence.

Conclusion : La documentation et le traitement du sevrage de l'alcool varient considérablement. On a établi un lien avec des doses plus faibles de benzodiazépines, un taux plus élevé de convulsions liées au sevrage et un séjour plus long à l'urgence. Une démarche normalisée fondée sur la prise en charge déclenchée par les symptômes devrait améliorer l'évolution de l'état de santé des patients qui se présentent en état de sevrage de l'alcool.

\section{Introduction}

Alcohol withdrawal is a common and serious problem in the emergency department (ED), accounting for 10\%-30\% of all ED visits in some studies. ${ }^{1-6}$ Patients with alcohol-related diagnoses are more likely to be frequent users of the $\mathrm{ED}$ and to require frequent ambulance transfers. ${ }^{7-9}$ Controlled trials have demonstrated that benzodiazepines reduce the intensity and duration of withdrawal and prevent complications such as seizures and delirium. ${ }^{10-12}$

"Symptom-triggered" treatment, where therapy is based on an objective withdrawal severity scale, ${ }^{13}$ provides more rapid and effective relief of withdrawal complications than subjective treatment based on clinicians' judgement alone. ${ }^{14-19}$ The most commonly used withdrawal severity scale is the Clinical Institute Withdrawal Assessment for Alcohol (CIWA-Ar) scale, a validated, reliable 10-item scale measuring tremor, sweating, anxiety and other signs of withdrawal; it can be performed in a few minutes. ${ }^{13}$ One example of symptom-triggered treatment is the diazepam-loading protocol, in which $20 \mathrm{mg}$ of oral diazepam is administered every hour if the patient's CIWA-Ar score is 10 or higher. ${ }^{12}$

The purpose of this study was to describe the management of alcohol withdrawal in 2 urban EDs, focusing on documentation of withdrawal severity, use of symptomtriggered benzodiazepine treatment, medications provided, ED length of stay and occurrence of seizures.

\section{Methods}

\section{Setting}

This retrospective chart audit was conducted at 2 urban hospitals in Toronto, Canada. Inner City Hospital (A) is a 350-bed community hospital with a high prevalence of alcohol- and drug-related problems. Downtown Teaching
Hospital (B) is a 420-bed hospital serving a community of mixed socio-economic status. Ethics approval was obtained at the 2 sites.

\section{Audit process}

The investigators developed a standard audit form and reviewed it in detail with the medical student who conducted the audits (N.L.). Information was collected on demographics, presenting complaint, ED length of stay (LOS), indicators of withdrawal severity (tremor, seizures), blood alcohol level (BAL), benzodiazepine dose administered, laboratory tests and consults ordered, discharge medications, and disposition. Prior to data collection, the student and the principal investigator (M.K.) audited 10 charts, clarified data definitions and reviewed discrepancies to maximize reliability.

\section{Patient eligibility}

A random sample of emergency charts with the ICD-9-CM $\operatorname{code}^{20}$ for alcohol withdrawal was reviewed for four 4month periods: June to September 1999 and 2000, and December to March 1999-2000 and 2000-2001. A random sample of charts with the ICD-9-CM code for alcoholism or alcohol-related problem was also audited. Charts were considered eligible for the study if they met at least one of the following criteria: admitting or discharge diagnosis of alcohol withdrawal; physicians' or nurses' notes describing alcohol withdrawal; mention of tremor or seizures; or a physician's ED order or discharge prescription for benzodiazepines.

\section{Outcomes}

Key outcome variables included total diazepam dose per patient, the occurrence of seizures in ED, and total ED length of stay, by hospital. 


\section{Data analysis}

Descriptive statistics for continuous variables were summarized using means and standard deviations. Categorical variables were summarized as frequencies. The statistical significance of observed differences in continuous outcome variables were determined using $t$ tests, and observed differences in categorical variables were analyzed using the chi-squared or Fisher's exact test for proportions, as appropriate. Unless otherwise specified, all significance tests are 2 -sided, and $p$ values $<0.05$ are considered significant.

\section{Results}

A total of 129 charts from Hospital A and 80 charts from Hospital B were audited. Neither hospital used the CIWA$\mathrm{Ar}$ or any other withdrawal severity scale for any of the 209 patient visits.

\section{Patient characteristics}

Table 1 shows that patient characteristics were similar at both hospitals. Most patients were male, and mean age was 45 years. Twenty-one percent of all patients had no family physician. Eighteen percent of the Hospital B patients had no fixed address or lived in a shelter. Most patients walked into the ED (52\%), and the Withdrawal Management Service (WMS), a non-medical detoxification unit, was the most common (29\%) source of referral for the Hospital A patients. In contrast, 39\% of Hospital B patients came by ambulance, and only 1 was sent by WMS. The most common presenting complaints for patients of both hospitals were alcohol withdrawal (26\%), intoxication (23\%), actual or expected seizures (18\%), medical clearance for WMS $(18 \%)$, tremor (15\%), and hallucinations, suicidal ideation or anxiety (12\%).

Patients were also similar in indicators of withdrawal severity, documented prevalence of tremors, history of prior seizures, and BAL on admission (Table 1). Tremor was noted in 161 patients (77\%) and not documented in $19 \%$. Prior seizure history was noted in 73 patients $(35 \%)$ and not documented in $52 \%$. There were no significant differences in documentation rates between the 2 hospitals.

\section{Key outcomes (Table 2)}

Most patients were treated with diazepam, including $88 \%$ at Hospital A and 78\% at Hospital B. For patients receiving more than 1 diazepam dose, the median total dose was $60 \mathrm{mg}$ and the time between the first and last dose was 6 hours for both hospitals. Thirty of 48 patients with no documented tremor received diazepam, and 20 patients $(9 \%)$ received their first dose of diazepam despite a BAL of greater than $35 \mathrm{mmol} / \mathrm{L}$. Table 2 shows that Hospital A provided higher diazepam doses $(63.9 \mathrm{mg}$ v. $25.9 \mathrm{mg} ; p<$ 0.001 ) and that this was associated with a lower rate of seizures in the ED: only $1(0.8 \%)$ of 129 Hospital A patients had seizures, compared to 7 (8.8\%) of 80 Hospital B patients $(p=0.02)$. All but 2 patients who had a convulsion had a history of prior seizures.

Patients spent an average of 9 hours and 40 minutes in the $\mathrm{ED}$, and the average number of nursing entries per patient was 9.3 , suggesting these patients require substantial nursing and treatment time. Of note, Hospital A patients had a shorter ED length of stay $(8 \mathrm{~h}, 38 \mathrm{~min}$ v. $10 \mathrm{~h}$,

\section{Table 1. Characteristics of patients presenting with alcohol with- drawal to 2 Toronto hospital emergency departments during the study periods}

\begin{tabular}{|c|c|c|c|}
\hline \multirow[b]{2}{*}{ Baseline variable } & \multicolumn{2}{|c|}{ No. of patients (and \%)* } & \multirow[b]{2}{*}{$p$ value } \\
\hline & $\begin{array}{c}\text { Hospital B十 } \\
n=80\end{array}$ & $\begin{array}{c}\text { Hospital A } \\
n=129\end{array}$ & \\
\hline Age in years, mean (and SD) & $43.22(11.60)$ & $46.58(11.47)$ & 0.04 \\
\hline Male gender (and SD) & $65(81.3)$ & $113(87.6)$ & 0.21 \\
\hline Unstable housing§ & $18(22.5)$ & $21(16.3)$ & 0.28 \\
\hline Tremor documented & $63(78.8)$ & $98(76.0)$ & 0.23 \\
\hline Prior history of seizures & $26(32.5)$ & $47(36.4)$ & 0.55 \\
\hline $\mathrm{BAL}=0$ on admission & $22 / 52(42)$ & $48 / 89(54)$ & 0.18 \\
\hline $\begin{array}{l}\text { Admission BAL (and SD) in } \\
\text { patients with BAL >0 }\end{array}$ & $\begin{array}{l}40.6(29.5) \\
n=30\end{array}$ & $\begin{array}{c}46.1(24.8) \\
\quad n=41\end{array}$ & 0.18 \\
\hline \multicolumn{4}{|c|}{$\begin{array}{l}\text { SD = standard deviation; BAL = blood alcohol level } \\
* \text { Unless otherwise indicated } \\
\text { H Hospital } B=420 \text {-bed downtown teaching hospital } \\
\text { F Hospital } A=350 \text {-bed inner city community hospital } \\
\S S \text { Shelter, or no fixed address } \\
\text { १Denominator indicates no. of patients who underwent alcohol testing; numerator indicates no. of } \\
\text { patients with BAL }=0 \text { on admission. }\end{array}$} \\
\hline
\end{tabular}


$15 \mathrm{~min}$ ) but this difference was not statistically significant $(p=0.19)$.

Based on chart documentation, 81 patients $(38.8 \%)$ were referred to WMS, 30 (14\%) were referred to social work or psychiatry, 30 (14\%) were advised to follow up with their family doctor and $3(1.4 \%)$ were referred to addiction medicine service or treatment program. Only 5 patients (2\%) had documented advice by the ED physician to reduce their alcohol consumption or attend an alcohol treatment program.

\section{Discussion}

This study demonstrates substantial variability in the management and outcomes of patients who present to the ED with alcohol withdrawal. Neither of these 2 busy urban EDs used an objective withdrawal severity scale such as the CIWA-Ar; key predictors like tremor and prior seizures were inconsistently documented; benzodiazepine doses were widely variable across sites; and many patients received diazepam despite high BALs or in the absence of documented tremor. The high seizure rate and relatively lower benzodiazepine dosing patterns seen at Hospital B suggests that patients might have been systematically undertreated at this site.

Since no objective measure of withdrawal severity was used, it is possible that patients at the 2 hospitals were different at baseline; however, we found no differences in terms of the available indicators of withdrawal severity in the documented prevalence of tremor, or with respect to prior seizure history. Groups also had similar risk factors for withdrawal severity, including age and admission BAL. ${ }^{21}$ Blood alcohol level correlates well with alcohol consumption in the past few hours, and the amount of alcohol consumption in the days immediately prior to admission is a risk factor for withdrawal severity. ${ }^{22}$ Not surprisingly, a high admission BAL is associated with a lower risk of withdrawal seizures in the $\mathrm{ED},{ }^{23}$ presumably because intoxicated patients are discharged from the ED before they go into severe withdrawal.

In this study, patients suffering from alcohol withdrawal spent an average of almost 10 hours in the ED, much longer than the average LOS for other non-admitted patients, which was 3 hours for Hospital A and 4.5 hours for Hospital B at the time of the study. Assuming patients at these hospitals received the appropriate total diazepam doses, their ED lengths of stay (time between first and last diazepam administration) could have been reduced from 6 hours to 1 hour (Hospital B), and from 6 hours to 2.75 hours (Hospital A) if diazepam was given $20 \mathrm{mg}$ every hour as recommended in a previously described diazepam loading protocol. ${ }^{12}$

Prior evidence suggests that brief physician advice is effective in reducing alcohol consumption among family medicine patients, medical inpatients and ED patients. ${ }^{24-27}$ Physicians should express concern, suggest treatment options such as Acoholics Anonymous or naltrexone, and advise family physician follow-up. Such advice can be pro-

\begin{tabular}{|c|c|c|c|}
\hline Variable & $\begin{array}{l}\text { Hospital } \mathrm{B}^{*} \\
\quad n=80\end{array}$ & $\begin{array}{l}\text { Hospital At } \\
n=129\end{array}$ & $p$ value \\
\hline Mean (and SD) diazepam dose $\neq$ & $\begin{array}{c}25.9 \mathrm{mg}(31.5) \\
\quad n=62\end{array}$ & $\begin{array}{l}63.9 \mathrm{mg}(43.6) \\
\quad n=113\end{array}$ & $<0.001$ \\
\hline $\begin{array}{l}\text { Mean (and SD) dose in patients with } \\
\text { prior seizures }(n=60) \S\end{array}$ & $9.9 \mathrm{mg}(4.4)$ & $19.9 \mathrm{mg}(0.6)$ & $<0.001$ \\
\hline Seizures in ED, no. of patients (and \%) & $7(8.8)$ & $1(0.8)$ & $0.021^{\pi}$ \\
\hline $\begin{array}{l}\text { First diazepam dose given while BAL } \\
\quad>35 \mathrm{mmol} / \mathrm{L} \text {, no. of patients (and } \% \text { ) }\end{array}$ & $6 / 15(40)$ & $14 / 26(54)$ & 0.39 \\
\hline $\begin{array}{l}\text { Time from first to last dosing, } \\
\text { mean (and SD)** }\end{array}$ & $\begin{array}{c}357 \min _{(n=31)}(303.5) \\
\end{array}$ & $\begin{array}{c}362.2 \min (472.0) \\
\quad(n=92)\end{array}$ & 1.00 \\
\hline ED length of stay, mean (and SD) & $8 \mathrm{~h}, 38 \mathrm{~min}(496 \mathrm{~min})$ & $10 \mathrm{~h}, 15 \mathrm{~min}(531 \mathrm{~min})$ & 0.19 \\
\hline Nursing entries, mean (and SD) & $7.68(7.08)$ & $10.24(8.55)$ & 0.03 \\
\hline $\begin{array}{l}\text { SD }=\text { standard deviation; } B A L=\text { blood alcohol level } \\
{ }_{*} \text { Hospital } B=420 \text {-bed downtown teaching hospital } \\
\text { tHospital } A=350 \text {-bed inner city community hospital } \\
\text { fDose per patient for those receiving at least } 1 \text { dose. } \\
\text { \$73 patients had prior seizures, but only } 60 \text { received d } \\
\text { TChi-squared } p=0.021 \text { (linear-by-linear association). } \\
* * \text { For patients receiving at least } 2 \text { doses. }\end{array}$ & epam. & & \\
\hline
\end{tabular}


vided in a few minutes or less, and from $10 \%-40 \%$ of patients referred from the ED to alcohol treatment programs will follow up as advised. ${ }^{28-30}$ Despite this, physicians in this study rarely counselled patients to reduce their alcohol consumption or attend an alcohol treatment program.

\section{Limitations}

This study has the usual limitations of a retrospective chart review. The lack of documentation of history, physical findings or advice does not necessarily mean that these were not done. Tremor rates may have been higher than documented, and the low rate of physician counselling and referral might reflect poor documentation; other studies have shown that physicians tend not to document advice about lifestyle issues. ${ }^{31}$ Because we did not follow up patients beyond the ED visit, we did not detect seizures or other adverse outcomes that occurred after ED discharge. While we advocate the use of the CIWA-Ar scale ${ }^{13}$ and a diazepam loading protocol, ${ }^{32,33}$ these have not been evaluated in the ED setting, and may require shortening or refinement to increase their feasibility for routine ED use.

\section{Conclusion}

There is significant variability in the ED documentation and treatment of alcohol withdrawal. Lower benzodiazepine dosing is associated with a higher rate of withdrawal seizures and prolonged ED lengths of stay. A standardized approach using symptom-triggered management is likely to improve outcomes for patients presenting to the ED with alcohol withdrawal.

Acknowledgements: Funding for this project came from St. Joseph's Health Centre and Mt. Sinai Hospital, both in Toronto, Ont.

Competing interests: None declared.

\section{References}

1. Cherpitel CJ, Soghikian K, Hurley LB. Alcohol-related health services use and identification of patients in the emergency department. Ann Emerg Med 1996;28(4):418-23.

2. el-Guebaly N, Armstrong SJ, Hodgins DC. Substance abuse and the emergency room: programmatic implications. J Addictive Diseases 1998;17(2):2-35.

3. Blake R, Brinker M, Ursic C, Clark J, Cox D. Alcohol and drug use in adult patients with musculoskeletal injuries. Am J Orthop 1997;26:704-10.

4. Lowenstein SR, Weissberg, MP Terry D. Alcohol intoxication, injuries, and dangerous behaviors--and the revolving emergency department door. J Trauma 1990;30:252-8.
5. Adams WL, Magruder-Habib K, Trued S, Broome HL. Alcohol abuse in elderly emergency department patients. J Am Geriatr Soc 1992;40(12):236-40.

6. Hulse GK, Robertson SI, Tait RJ. Adolescent emergency department presentations with alcohol- or other drug-related problems in Perth, Western Australia. Addiction 2001;96(7):1059-67.

7. Kriegsman W, Anthes W. The financial impact of alcohol-related emergencies on a rural EMS system. Alaska Med 1998; 40(1):7-11.

8. Mandelberg JH, Kuhn RE, Kohn MA. Epidemiologic analysis of an urban, public emergency department's frequent users. Acad Emerg Med 2000;7(6):637-46.

9. Brokaw J, Olson L, Fullerton L, Tandberg D, Sklar D. Repeated ambulance use by patients with acute alcohol intoxication, seizure disorder, and respiratory illness. Am J Emerg Med 1998;16(2):141-4.

10. Adinoff B. Double-blind study of alprazolam, diazepam, clonidine, and placebo in the alcohol withdrawal syndrome: preliminary findings. Alcohol Clin Exp Res 1994;18(4):873-8.

11. Naranjo CA, Sellers EM, Chater K, Iversen P, Roach C, Sykora K. Nonpharmacologic intervention in acute alcohol withdrawal. Clin Pharmacol Ther 1983;34(2):214-9.

12. Devenyi P, Harrison ML. Prevention of alcohol withdrawal seizures with oral diazepam loading. CMAJ 1985;132(7):798-800.

13. Sullivan JT, Sykora K, Schneiderman J, Naranjo CA, Sellers EM. Assessment of alcohol withdrawal: the revised clinical institute withdrawal assessment for alcohol scale (CIWA-Ar). Br J Addict 1989;84(11):1353-7.

14. Jaeger TM, Lohr RH, Pankratz VS. Symptom-triggered therapy for alcohol withdrawal syndrome in medical inpatients. Mayo Clin Proc 2001;76(7):695-701 .

15. Wasilewski D, Matsumoto H, Kur E, Dziklinska A, Wozny E, Stencka K, et al. Assessment of diazepam loading dose therapy of delirium tremens. Alcohol Alcohol 1996;31(3):273-8.

16. Saitz R, Mayo-Smith MF, Roberts MS, Redmond HA, Bernard DR, Calkins DR. Individualized treatment for alcohol withdrawal. A randomized double-blind controlled trial. JAMA 1994;272(7):519-23.

17. Daeppen JB, Gache P, Landry U, Sekera E, Schweizer V, Gloor $\mathrm{S}$, et al. Symptom-triggered vs fixed-schedule doses of benzodiazepine for alcohol withdrawal: a randomized treatment trial. Arch Intern Med 2002;162(10):1117-21.

18. Mayo-Smith MF. Pharmacological management of alcohol withdrawal. A meta-analysis and evidence-based practice guideline. American Society of Addiction Medicine Working Group on Pharmacological Management of Alcohol Withdrawal. JAMA 1997;278(2):144-5.

19. Holbrook AM, Crowther R, Lotter A, Cheng C, King D. Metaanalysis of benzodiazepine use in the treatment of acute alcohol withdrawal. CMAJ 1999;160(5):649-55. 
20. International Classification of Diseases, 9th Revision (Clinical Modification). 5th ed. Washington: US Department of Health and Human Services; 1996. Cat no 86-72897.

21. Brower KJ, Mudd S, Blow FC, Young JP, Hill EM. Severity and treatment of alcohol withdrawal in elderly versus younger patients. Alcohol Clin Exp Res 1994;18(1):196-201.

22. Pristach CA, Smith CM, Whitney RB. Alcohol withdrawal syndromes - prediction from detailed medical and drinking histories. Drug Alcohol Depend 1983;11(2):177-99.

23. Rathlev NK, Ulrich A, Fish SS, D'Onofrio G. Clinical characteristics as predictors of recurrent alcohol-related seizures. Acad Emerg Med 2000;7(8):886-91.

24. Fleming MF, Barry KL, Manwell LB, Johnson K, London R. Brief physician advice for problem alcohol drinkers. A randomized controlled trial in community-based primary care practices [see comments]. JAMA 1997;277( 3):1039-45.

25. Gentilello LM, Rivara FP, Donovan DM, Jurkovich GJ, Daranciang E, Dunn CW, et al. Alcohol interventions in a trauma center as a means of reducing the risk of injury recurrence. Ann Surg 1999;230(4):473-80; discussion 480-3.

26. Monti PM, Colby SM, Barnett NP, Spirito A, Rohsenow DJ, Myers M, et al. Brief intervention for harm reduction with alcohol-positive older adolescents in a hospital emergency department. J Consult Clin Psychol 1999;67(6):989-94.

27. Hungerford DW, Pollock DA, Todd KH. Acceptability of emergency department-based screening and brief intervention for al- cohol problems. Acad Emerg Med 2000;7(2):1383-92.

28. Green M, Setchell J, Hames P, Stiff G, Touquet R, Priest R. Management of alcohol abusing patients in accident and emergency departments. J R Soc Med 1993;86(7):393-5.

29. Batel P, Pessione F, Bouvier AM, Rueff B. Prompting alcoholics to be referred to an alcohol clinic: the effectiveness of a simple letter. Addiction 1995;90(6):811-4.

30. Bernstein E, Bernstein J, Levenson S. Project ASSERT: an EDbased intervention to increase access to primary care, preventive services, and the substance abuse treatment system. Ann Emerg Med 1997;30(2):181-9.

31. Rumpf HJ, Bohlmann J, Hill A, Hapke U, John U. Physicians' low detection rates of alcohol dependence or abuse: a matter of methodological shortcomings? Gen Hosp Psychiatry 2001; 23(3):33-7.

32. Foy A, March S, Drinkwater V. Use of an objective clinical scale in the assessment and management of alcohol withdrawal in a large general hospital. Alcohol Clin Exp Res 1988;12(3): 360-4.

33. Salloum IM, Cornelius JR, Daley DC, Thase ME. The utility of diazepam loading in the treatment of alcohol withdrawal among psychiatric inpatients. Psychopharmacol Bull 1995;31(2):305-10.

Correspondence to: Dr. Meldon Kahan, Medical Director, Addiction Medicine Service; St. Joseph's Health Centre, 33 The Queensway, Toronto ON M6R 1B5; 416 530-6860, fax 416 530-6160, kahanm@stjoe.on.ca 